\title{
Correspondence
}

We welcome letters to the Editor concerning articles which have recently been published. Such letters will be subject to the usual stages of selection and editing; where appropriate the authors of the original article will be offered the opportunity to reply.

Letters should normally be under 300 words in length, double-spaced throughout, signed by all authors and fully referenced. The edited version will be returned for approval before publication.

\section{Recurrence of giant-cell tumour of bone after the use of cement}

Sir,

I have read with interest the paper by Remedios et al in the January 1997 issue entitled 'Radiological and clinical recurrence of giant-cell tumour of bone after the use of cement'. The description of radiolucency as an important indicator of recurrence underscores the value of plain radiography for evaluating the clinical course of such tumours.

The paper compares clinical and radiological detection of recurrence and reaches the conclusion that the recurrence of giant-cell tumour (GCT) is detected earlier radiologically than clinically, by four months on average. Of the 51 recurrences investigated in the study of Campanacci et $\mathrm{al}^{2}, 90 \%$ appeared during the first three years after operation with a few being seen after a delay of nine years.

Remedios et al carried out radiological follow-up at two weeks, six weeks, three months, four months and six months after surgery. I and my colleagues disagree with their practice of performing ten radiographs during the first six months and then stopping frequent radiological monitoring two years after operation. It has been our experience that most recurrences take place between 6 and 18 months postoperatively. They do not discuss the importance of conventional tomography and CT.

We undertake a medical review four times in the first year which includes physical examination and conventional radiography. During the second year, two examinations (including radiography) are scheduled. Before removing the cement and bone graft after two years, or in cases in which local recurrence is suspected, conventional tomograms and a CT-guided needle biopsy are performed. We do not believe that the radiopaque artefacts produced by cement in $\mathrm{CT}$ scans pose as serious a problem as the tiny metal residues left by the bone cutter used for tumour excision, which often lead to erroneous interpretation of MRI. Moreover, CT appears to be superior to MRI for assessing normal bone near the cement border.

U. QUINT, MD

University of Essen

Essen, Germany.

1. Remedios D, Saifuddin A, Pringle J. Radiological and clinical recurrence of giant-cell tumour of bone after the use of cement. J Bone Joint Surg [Br] 1997;79-B:26-30.

2. Campanacci M, Baldini N, Boriani S, Sudanese A. Giant-cell tumor of bone. J Bone Joint Surg [Am] 1987;69-A:106-14.

(C1998 British Editorial Society of Bone and Joint Surgery 0301-620X/98/28748 $\$ 2.00$

J Bone Joint Surg [Br] 1998;80-B:370-2.

\section{Author's reply:}

Sir,

I thank Dr Quint for his interest in our paper. With reference to the study of Campanacci et al, ${ }^{1}$ our experience has been different. We have found that most lesions recur within the first year. We continue to review patients at least annually after two years although this point was possibly not made clear in the paper. As far as conventional tomography and CT are concerned in the assessment of recurrence, we do not see any place for these investigations since MRI has become available. We have also not experienced the problem of tiny metal residues left by the bone cutter when scanning these patients with MRI. It is not our practice to remove the acrylic cement after two years.

The aim of our paper was to highlight the importance of careful evaluation of plain radiographs at follow-up in these patients, since in our experience they can demonstrate evidence of recurrence well before there is any clinical suspicion.

A. SAIFUDDIN, FRCR

Royal National Orthopaedic Hospital

Stanmore, UK.

1. Campanacci M, Baldini N, Boriani S, Sudanese A. Giant-cell tumor of bone. J Bone Joint Surg [Am] 1987;69-A:106-14.

\section{Thromboprophylaxis and death after total hip replacement}

Sir,

In their article in the November 1996 issue entitled 'Thromboprophylaxis and death after total hip replacement' Murray, Britton and Bulstrode ${ }^{1}$ have highlighted the long-ignored need for a change in emphasis from radiological to clinical trials. Until such information is available, however, orthopaedic surgeons must be careful as to how they interpret these results.

They show that there is no evidence that thromboprophylaxis reduces clinical events, but this does not mean that thromboprophylaxis does not lessen such outcomes. The semantic distinction is important, particularly when we consider the important biases in the study including the use of pooled data, routine screening for thrombosis in clinical trials and the use of opportunist data, some of which the authors acknowledge; these can mask a small reduction in death rate.

A rate of fatal pulmonary embolism of $0.2 \%$ to $0.3 \%$ still represents 80 to 120 deaths each year in England and Wales after total hip replacement. Even a small reduction would be important, although probably impossible to prove statistically.

Until large trials have been undertaken, or until we can reliably identify high-risk patients, orthopaedic surgeons must decide whether the current radiological evidence implies that it is more likely than not that prophylaxis reduces the risk of clinical thromboembolism. They must consider the unvalidated assumption that a reduction in radiological thrombosis represents a reduction in clinical thromboembolism. If, on balance, they believe this to be the case, they should choose a method which carries the least risk of side-effects, such as the use of lowmolecular-weight heparin or, in particular, foot impulse pumps. If not, they must accept that occasional fatal emboli will occur and 
hope that future science will reassure them that these deaths could not have been prevented.

D. WARWICK, FRCS, FRCS Orth

University of Bristol

Bristol, UK.

1. Murray DW, Britton AR, Bulstrode CJK. Thromboprophylaxis and death after total hip replacement. J Bone Joint Surg [Br] 1996;78-B: 863-70.

\section{Author's reply:}

Sir,

We are grateful to Mr Warwick for reinforcing our view that the finding that prophylactic drugs did not cause a significant decrease in fatal pulmonary embolism (FPE) does not necessarily mean that such drugs do not prevent it. In our paper we took this argument further. We stated that meta-analysis from all fields of medicine and surgery suggests that both heparin and aspirin may decrease the rate of FPE, and we calculated that these drugs may decrease this after total hip replacement by about $0.05 \%$.

Anticoagulant drugs, however, are likely to have risks as well as benefits since they probably contribute to deaths from other causes. If they cause more deaths than the very few $(0.05 \%)$ which they may prevent, they are actually harmful. To balance the risks and benefits we studied the overall death rate. Since we found no evidence of a decrease in this we concluded that guidelines recommending the routine use of pharmacological thromboprophylaxis to decrease the death rate were not justified.

If there is a method of preventing FPE without other risk it should be used. It is possible that foot impulse pumps will achieve this, but there is as yet no evidence that they do and, similarly, there is little information about their risks. The most desirable agent would be one which prevented FPE and decreased death from other causes. Aspirin may be such an agent, but there is not yet enough evidence to prove this.

D. W. MURRAY, MD, FRCS Orth

Nuffield Orthopaedic Centre

Oxford, UK

\section{MRI can prevent unnecessary arthroscopy}

Sir,

In their article in the July 1997 issue entitled 'MRI can prevent unnecessary arthroscopy' Carmichael et al ${ }^{1}$ state that MRI of the knee is cheaper than arthroscopy. In Denmark the cost of MRI is 5000 Danish crowns while the price of a diagnostic arthroscopy is 1800 crowns and with a meniscectomy 2200 crowns.

J. V. BRUUN, MD

Ortopaed Kirurgisk Klinik

Køge, Denmark.

1. Carmichael IW, MacLeod AM, Travlos J. MRI can prevent unnecessary arthroscopy. J Bone Joint Surg [Br] 1997;79-B:624-5.

Sir,

I read with interest the article in the July 1997 issue entitled 'MRI can prevent unnecessary arthroscopy' by Carmichael et al. ${ }^{1}$ I fully agree with the authors that diagnostic arthroscopy is not necessary nowadays and that MRI allows us to be more precise in our indications for operation. A diagnostic method, however, is only as good as the person who interprets it, and scans should not be undertaken without thorough clinical appraisal to determine their possible value.

M. H. SCHWARZ, MD

SMZO-Donauspital Wien

Vienna, Austria.

1. Carmichael IW, MacLeod AM, Travlos J. MRI can prevent unnecessary arthroscopy. J Bone Joint Surg [Br] 1997;79-B:624-5.

Sir,

In their paper in the July 1997 issue entitled 'MRI can prevent unnecessary arthroscopy' the authors have commendably attempted to prove what for many surgeons is probably a standard part of their orthopaedic practice. It is not apparent from their study, however, what the final outcome was for those patients in whom MRI was negative. In my experience these patients are often not followed up properly and may later present for a second opinion, often to another team, and consequently be listed for arthroscopy.

The assumption that MRI would have been normal in the 28 patients with negative diagnostic arthroscopies is also dangerous, particularly since these patients were not operated on by the designated knee specialist for whom the negative arthroscopy rate was only $11 \%$ as opposed to the $24 \%$ for the 'non-knee specialist'. The authors suggest that clinical diagnosis was "probably better" in the patients under the 'knee specialist'.

\section{P. WILLIAMS, FRCS}

Morriston Hospital

Swansea, UK

1. Carmichael IW, MacLeod AM, Travlos J. MRI can prevent unnecessary arthroscopy. J Bone Joint Surg [Br] 1997;79-B:624-5.

\section{Author's reply:}

Sir,

We thank Dr Bruun for his comments. We acknowledge that there are variations in the price of arthroscopy and MRI not only from country to country but also from region to region within the same country. This may influence decision-making. We do, however, feel strongly that it is better to make a diagnosis by non-invasive means. If this is enough to reassure the patient and prevent unnecessary surgery, then we believe that it is preferable.

The point made by Dr Schwarz that a good history and thorough examination are the basis of good clinical practice is well taken. In our article we are not advocating neglect of this principle. Our view is that MRI should be ordered by the surgeon who is capable of performing the necessary surgery. He will have more experience in making a clinical diagnosis, thus avoiding unnecessary repeated MRI.

We accept the point made by Mr Williams that patients with a negative MRI may go to another orthopaedic surgeon and have arthroscopy. We also agree that patients with a negative arthroscopy may not all have had normal MRI. We feel, however, that MRI is unlikely to have shown positive indications to proceed to arthroscopic surgery if the arthroscopy was negative.

J. TRAVLOS, FCS(SA)Orth, MMedOrth

Staffordshire General Hospital

Stafford, UK. 


\section{Early tourniquet release during total knee arthroplasty}

Sir,

We read with interest the paper by Barwell et al entitled 'The effects of early tourniquet release during total knee arthroplasty, 1 in the March 1997 issue.

We wish to draw attention to a previous study ${ }^{2}$ which showed results contrary to those published by Barwell et al.

A notable benefit of not releasing the tourniquet following total knee replacement (TKR) until after wound closure was not mentioned in their paper. We routinely attempt to salvage blood lost during TKR. If the tourniquet is not released until after wound closure the entire amount is potentially salvageable. We are able to collect an average of $70 \%$ of the total blood loss, which is then reinfused. As a result, only $15 \%$ of our patients undergoing TKR require allogeneic blood transfusion.

While we acknowledge that Barwell et al appear to show some advantages with the early release of the tourniquet, we believe that these are outweighed by the potential to reduce drastically the need for allogeneic blood transfusion with its associated risks.

M. S. HENDERSON, FRCS

J. H. NEWMAN, FRCS

C. G. HAND, FRCS

Avon Orthopaedic Centre

Southmead Hospital

Bristol, UK.

1. Barwell J, Anderson G, Hassan A, Rawlings I. The effects of early tourniquet release during total knee arthroplasty: a prospective randomised double-blind study. J Bone Joint Surg [Br] 1997;79-B: 265-80.

2. Newman JH, Jackson JP, Waugh W. Timing of tourniquet release after knee replacement. J R Soc Med 1979;72:492-4.

3. Majkowski RS, Currie IC, Newman JH. Postoperative collection and reinfusion of autologous blood in total knee arthroplasty. Ann $R$ Coll Surg Engl 1991;73:381-4.

4. Newman JH, Bowers M, Murphy J. The clinical advantages of autologous transfusion: a randomised, controlled study after knee replacement. J Bone Joint Surg [Br] 1997;79:630-2.

\section{Authors' reply:}

Sir,

We thank Mr Henderson and his colleagues for their interest in our paper.

The previous study which they quote ${ }^{1}$ was primarily concerned with the effect of the timing of tourniquet release on overall blood loss, not on pain and early postoperative function. We only assessed blood loss indirectly, by the decrease in haemoglobin concentration, but our conclusion was exactly that of the previous study in that blood loss was unaffected by the timing of the release.

Interestingly, the second two studies quoted ${ }^{2,3}$ report a wound complication rate of about $20 \%$, very similar to that of our group with late release of the tourniquet.

We recognise the value of autologous blood transfusion and feel that early tourniquet release in no way precludes its use. Intraoperative red cell salvage is an alternative but becomes financially viable only if two units or more are salvaged. The compromise, as suggested by Slagis et al, ${ }^{4}$ of proceeding with washing and processing the collected blood only if sufficient volume has been collected, seems sensible. If too little bleeding occurs then only the cost of collection is incurred. It is possible that these latter patients do not require transfusion despite a decrease in haemoglobin concentration.

Much of the expense of homologous blood transfusion is in the cross-matching process itself. Intraoperative collection and obser- vation of the blood loss while the patient is under anaesthesia could perhaps give clinicians the confidence not to cross-match blood routinely before operation.

J. BARWELL, FRCS

G. ANDERSON, FRCS Orth, FRCS

A. HASSAN, DrChOrth

I. RAWLINGS, FRCS

1. Newman JH, Jackson JP, Waugh W. Timing of tourniquet release after knee replacement. J Soc Med 1979;72:492-4.

2. Majkowski RS, Currie IE, Newman JH. Postoperative collection and reinfusion of autologous blood in total knee arthroplasty. Ann R Coll Surg Eng 1991;73:381-4.

3. Newman JH, Bowers M, Murphy J. The clinical advantages of autologous transfusion: a randomised, controlled study after knee replacement. J Bone Joint Surg [Br] 1997;79-B:630-2.

4. Slagis VS, Benjamin JB, Volz GV, Giordano GF. Postoperative blood salvage in total hip and knee arthroplasty: a randomised control trial. J Bone Joint Surg [Br] 1991;73-B:591-4.

\section{Alternative treatments for meniscal injuries}

Sir,

In the Instructional Course Lecture by Verdonk ${ }^{1}$ entitled 'Alternative treatments for meniscal injuries' in the September 1997 issue, he mentions that one of the functions of the meniscus is 'shock absorption'. Does he know of any experimental evidence which shows that menisci attenuate shock waves and that they do so by virtue of their viscoelastic properties? I believe that the menisci distribute loads at different positions of the joint and that they contribute to stabilisation of the femoral condyles on the tibia, but their capacity to absorb energy is traditionally overrated.

Shock waves or the peak forces of gait can be lowered by elastic deformation and storage of energy. The capacity of the menisci for this is limited as indicated by meniscal tears. Energy can also be absorbed by liquid flow in viscoelastic material which is time-dependent. At high loading rates very little flow occurs and the behaviour of the structure is rather stiff, again shown by meniscal tears.

Most damping or shock absorption takes place by eccentric contraction of the muscles across the knee, principally the quadriceps. 'Shock absorption' is a misused term in this context.

R. KÖLBEL, MD

Alte Landstrasse 258

Hamburg, Germany.

1. Verdonk R. Alternative treatments for meniscal injuries. J Bone Joint Surg [Br] 1997;79-B:866-73.

\section{Author's reply:}

Sir,

I thank Professor Kölbel for his comment. I know of only one recent paper which deals with the shock-absorbing qualities of the meniscus. The authors applied a load to 20 cadaver knees and found that when a radial cut was made in both menisci, the transmitted force increased by $13 \%$. After the menisci and the soft tissues had been removed the increase was $21 \%$. This may indicate that menisci do have shock-absorbing capacities. The mechanism involved and the relevance in vivo remain to be investigated.

R. VERDONK, MD, MCh Orth

Ghent University Hospital

Ghent, Belgium

1. Hoshino A, Wallace WA. Impact-absorbing properties of the human knee. J Bone Joint Surg [Br] 1987;69-B:807-11. 